\title{
Uso de aditivo alimentar equilibrador da flora intestinal em aves de corte e de postura
}

\section{Use of a balancing food additive of the intestinal flora for broilers and laying}

\author{
Marina Jorge de Lemos ${ }^{1 *}$, Lígia Fátima Lima Calixto', Karoll Andrea Alfonso Torres-Cordido², \\ Túlio Leite Reis ${ }^{1}$
}

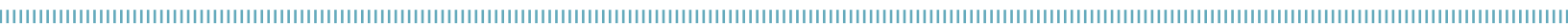

RESUMO: Aspectos gerais sobre a utilização de aditivos zootécnicos equilibradores da flora intestinal em rações de aves de corte e de postura foram abordados nesta revisão, destacando-se a utilização de prebióticos, especialmente dos mananoligossacarídeos (MOSs), os quais promovem o crescimento das populaçóes microbianas que melhoram as condiçốes luminais. A utilização de aditivos equilibradores da flora intestinal tem revelado melhorias na integridade do epitélio intestinal (aumento da altura e largura das vilosidades), no desempenho (melhora na produção e conversão alimentar) e na qualidade do produto final (qualidade da casca dos ovos). Esta revisão objetivou abordar também aspectos relacionados às características, ao mecanismo de ação, além dos efeitos benéficos da utilização desses aditivos alternativos aos antibióticos na avicultura de corte e de postura, incluindo codornas japonesas.

PALAVRAS-CHAVE: aditivo alternativo; integridade intestinal; prebiótico.

\begin{abstract}
The general aspects on the use of zootechnical additives that balance the intestinal flora in diets of broilers and laying were reviewed, highlighting the use of prebiotics, mainly Mannan-oligosaccharides (MOS). These promote the growth of microbial population, thus improving luminal conditions. The use of additives balancing the intestinal flora has been shown to improve the integrity of the intestinal epithelium (increased villus height and width), performance (improvement in production and feed conversion), and quality of the final product (quality of shell eggs). This review also addresses issues related to the characteristics, mechanism of action, in addition to the beneficial effects of using these additives as an alternative to antibiotics in the poultry production, including Japanese quail.
\end{abstract}

KEYWORDS: alternative additive; intestinal integrity; prebiotic. 
A avicultura de corte e de postura representa um dos setores que mais tem se desenvolvido no agronegócio brasileiro, apresentando altas taxas de produtividade, desenvolvimento tecnológico de instalaçóes e equipamentos, assim como muitos avanços em nutrição e sanidade. O Brasil está entre os maiores produtores e exportadores de carne de frango do mundo, o que tem contribuído para o desenvolvimento econômico do país. A busca pela obtenção de alta produtividade, aliada à qualidade dos produtos finais, tem sido uma constante na produção intensiva de aves. No entanto, alcançar alta produtividade, mantendo o custo baixo, é quase impossível sem a utilização de aditivos alimentares (ОтUтUмі et al., 2008), como o composto denominado, segundo o Compêndio Brasileiro de Alimentação Animal (2009), aditivo zootécnico equilibrador da flora intestinal. Esse pode ser adicionado à ração e desempenhar papel estratégico, atuando tanto na integridade quanto no desenvolvimento da mucosa intestinal, e melhorando, consequentemente, o desempenho do lote.

O trato gastrintestinal (TGI) das aves possui uma microbiota natural composta por muitas espécies de bactérias, protozoários e fungos em equilíbrio entre si e com o hospedeiro. A presença dessa microbiota em equilíbrio é tão necessária quanto benéfica para o bem-estar das aves, pois o desequilíbrio, em favor das bactérias indesejáveis, pode resultar em danos para a mucosa intestinal e prejuízos na absorção dos nutrientes da ração, com consequente comprometimento no desempenho produtivo (LodDI, 2003). Aditivos melhoradores de desempenho, a exemplo dos antibióticos, têm sido utilizados nas últimas décadas na tentativa de, por meio de exclusão competitiva, manter o equilíbrio benéfico da microbiota do TGI, reduzindo a mortalidade e aumentando a eficiência produtiva das aves (SAlYers, 1999; CASTANON, 2007).

É inquestionável que a relação custo-benefício favorece o uso de antibióticos como aditivos, mas, após a proibição do uso de aditivos antibióticos melhoradores de desempenho pela União Europeia, vem surgindo um grande interesse por parte dos pesquisadores brasileiros no desenvolvimento de pesquisas com a utilização de substâncias que possam substituir os antibióticos e que possam desempenhar funçóes que revertam em melhor desempenho das aves e qualidade do produto final.

Esta revisão objetivou abordar aspectos relevantes em relação às características, à utilização e ao mecanismo de ação de aditivo equilibrador da flora intestinal, com ênfase nos prebióticos (frutoligossacarídeo - FOS, glucoligossacarídeo - GOS, e mananoligossacarídeo - MOS), para aves de corte e de postura.

No Brasil, a utilização de melhoradores de desempenho (antibióticos) na dieta de aves ainda é permitida; no entanto, o banimento progressivo de vários antibióticos de uso comum nas raçôes já é realidade em muitos países, o que vem suscitando reações na indústria avícola, como a busca por substâncias que possam substituí-los (Ferreira; Astolfi-Ferreira, 2006). Os prebióticos são compostos que têm despertado grande interesse na área avícola quando utilizados na forma de aditivos, representando uma alternativa promissora para substituir os antibióticos, especialmente em aves jovens ou em condiçóes de estresse (Silva; Nörnberg, 2003).

Os prebióticos atuam mantendo o equilíbrio benéfico da microbiota intestinal e a integridade do epitélio intestinal, além de ter ação melhoradora sobre o sistema imunológico, objetivando, dessa forma, a manutenção ou o incremento no desempenho animal e na qualidade do produto final (SiLva; Nörnberg, 2003). Para que seja considerada um prebiótico, a substância não pode ser hidrolisada no TGI e deve ter ação seletiva somente para um limitado número benéfico de bactérias comensais, as quais terão crescimento e metabolismo estimulados, alterando favoravelmente a microbiota intestinal (Dionízio et al., 2002).

As principais fontes de prebióticos são alguns açúcares, absorvíveis ou não, fibras, peptídeos, proteínas, alcoóis de açúcares e os oligossacarídeos de cadeia curta. Outros compostos que também podem ser classificados como prebióticos para aves são os dissacarídeos transgalactosilatados (Rowland, 1992). Os prebióticos que têm sido mais estudados como aditivos nas raçóes para animais não ruminantes e operando de forma distinta são os oligossacarídeos de cadeias curtas de açúcares simples, especialmente os FOSs, GOSs e MOSs (Macari; Furlan, 2005).

Os GOSs têm seus efeitos prebióticos pouco pesquisados para animais. Eles são muito relacionados e analisados pelo seu efeito bifidogênico em humanos (Bounnik et al., 1997). São oligossacarídeos compostos por lactose e várias moléculas de galactose que não são digeridos no trato digestivo superior devido às suas ligações $\beta$ - $(1,6)$ e $\beta$ - $(1,4)$, que evitam a digestão pela enzima $\beta$-galactosidase (Alles et al., 1999). Este prebiótico é assimilado por espécies de Bifidobacterium, sendo substrato para estas; entretanto, tal assimilação não é possível por espécies patogênicas, incluindo Clostridium e Salmonella, fato que propicia a proliferação de espécies benéficas em detrimento das patogênicas (IJi; Tivey, 1998). Biggs et al. (2007), após o fornecimento de GOS para frangos de corte, observaram melhora na digestibilidade dos nutrientes da ração, sem efeito negativo sobre o desempenho. Jung et al. (2008), ao estudar os efeitos da inclusão de GOS associado ou não com probiótico para frangos de corte, concluíram que os GOSs têm efeitos prebióticos importantes, como aumento da população de bactérias benéficas, tais como as bifidobactérias.

Os FOSs são polímeros ricos em frutose, podendo ser naturais (derivados de plantas, como a inulina) ou sintéticos (resultantes da polimerização da frutose) (GIBSON; RobERFROID, 1995). A inulina é um polímero da frutose, indigerível na porção superior do trato intestinal (KNudsen; Hessov, 1995), que alcança o intestino grosso praticamente intacto, no qual é fermentada pelas bactérias benéficas (Acidophillus, Bifidus e Faecium) e convertida em ácidos graxos de cadeia curta (acetato, propionato e butirato), lactato e gases, minimizando as populaçóes de bactérias patogênicas, como a Escherichia coli e a 
Salmonella, por exclusão competitiva (SCAPINELlo et al., 2001). Esse FOS pode reduzir a contagem de coliformes e o $\mathrm{pH}$ cecal e aumentar a contagem de bifidobactérias cecais benéficas ao intestino das aves. $\mathrm{Xu}$ et al. (2003), trabalhando com frangos de corte alimentados com dieta contendo diferentes níveis de inclusão (2,0 e 4,0 $\mathrm{g} \mathrm{kg}^{-1}$ de FOSs), observaram um aumento da concentração cecal de bifidobactérias e lactobacilos e uma redução da concentraçáo de $E$. coli no intestino de frangos aos 49 dias de idade. Os autores concluíram que o nível ótimo de suplementação com FOS a frangos de corte para aumentar o ganho de peso e a eficiência alimentar deve ser mantido entre 2,5 e 5,0 $\mathrm{g} \mathrm{kg}^{-1}$. O crescimento de salmonela entérica sorovar Typhimurium em um sistema de fermentaçáo in vitro foi inibido nos tratamentos em que o FOS foi adicionado (Donalson et al., 2007).

Um prebiótico que tem sido muito estudado e utilizado atualmente é a parede celular de Saccharomyces cerevisiae (MACARI; FurLAN, 2005), que é produto da extração do conteúdo celular da levedura $S$. cerevisiae, fungo unicelular aeróbio obrigatório ou anaeróbio facultativo, utilizada pelos homens há milhares de anos para produção de alimentos e bebidas. Essa estrutura (Fig. 1) é rica em um oligossacarídeo à base de alfa-manose e beta-glucose (Kogan; Kocher, 2007), chamado de MOS. É considerada uma das leveduras mais antigas utilizada pelo ser humano há milhares de anos para produção de alimentos e bebidas e na alimentação animal, além de ser descrita na literatura por trazer benefícios no âmbito sistêmico, melhorando o ganho de peso (ZaGHINI et al., 2005), o consumo de alimentos e a conversão alimen$\operatorname{tar}$ (SANTiN et al., 2001). O MOS é derivado da parede celular interna de leveduras $S$. cerevisiae e é composto por uma estrutura complexa de manose fosforilada, glicose e proteína. A parede celular é obtida separando-a do conteúdo intracelular e evaporando a baixa temperatura (spray dry), evitando a destruição da parte funcional da molécula de MOS (SPRING et al., 2000).

O MOS atua por meio de mecanismos mais complexos, podendo se aderir às bactérias patogênicas, impedindo que estas iniciem um processo de colonização, ou modulando e preparando o sistema imunológico, para proteçáo contra um processo infeccioso. Em relação ao primeiro mecanismo, sabe-se que para

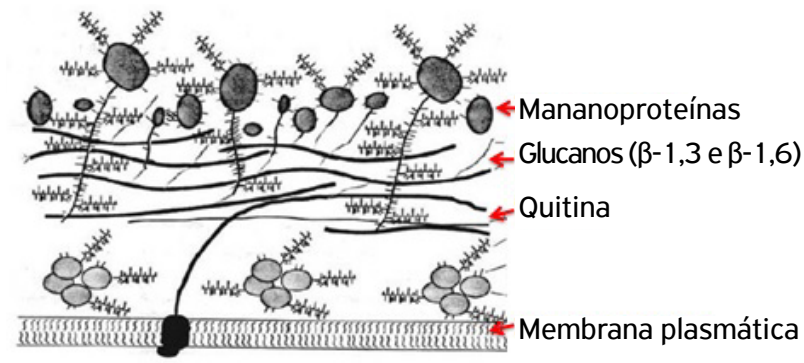

Fonte: adaptado de Gomes (2002).

Figura 1. Composição e estrutura da parede celular da S. cerevisiae. uma bactéria iniciar o processo infeccioso é necessário que ela consiga se aderir à superfície epitelial. Tal adesão é possível em função de grande atração das glicoproteínas (lectinas) presentes nas fímbrias pelos oligossacarídeos. Os prebióticos derivados da parede celular de $S$. cerevisiae têm predileçâo por esses sítios de ligação, ocupando e impossibilitando a adesão de bactérias patogênicas e eliminando-as junto ao bolo fecal (PeLícia, 2004). As fímbrias, com características hemaglutinantes manose-sensíveis, têm grande incidência registrada entre as enterobactérias (SHANe, 2001), estando presentes na Salmonella sp. e na E. coli. (Matheus et al., 2003). A força de adesão entre o patógeno e o MOS (Fig. 2) inibe o processo de infecção, náo permitindo que a bactéria volte a infectar o animal (NEwMAN, 2007). O MOS também se adere à mucosa intestinal, formando uma barreira física que impede a colonização intestinal por organismos agressores (Pelicano et al., 2002).

O segundo mecanismo de ação está relacionado com a ativaçâo do sistema imunológico das aves. Os prebióticos podem atrair células e outros componentes imunológicos para o trato intestinal, aumentando a barreira contra antígenos na mucosa (CotTer, 1994). O MOS, por exemplo, é capaz de estimular o sistema imunológico ao se ligar a sítios receptores de macrófagos na superfície de enterócitos após o reconhecimento de açúcares específicos nesse epitélio. Essa ligação desencadeia uma reação em cascata, com a ativação de macrófagos e liberação de citocinas, caracterizando uma resposta imunológica adquirida (SAVAGE et al., 1997). Dessa forma, o MOS é capaz de aumentar os níveis de anticorpos circulantes específicos e a síntese de imunoglobulinas secretórias em resposta à exposição a antígenos (Savage et al., 1997). Savage et al. (1997) testaram o efeito do MOS em perus e constataram um aumento significativo de IgG plasmático e IgA da bile. Spring; Privulescu (1998) constataram aumento na resposta de macrófagos e acréscimo de aproximadamente $25 \%$ dos níveis de imunoglobulina tipo A (IgA) secretória quando foi adicionado MOS na ração de frangos de corte. Por outro lado, existem relatos

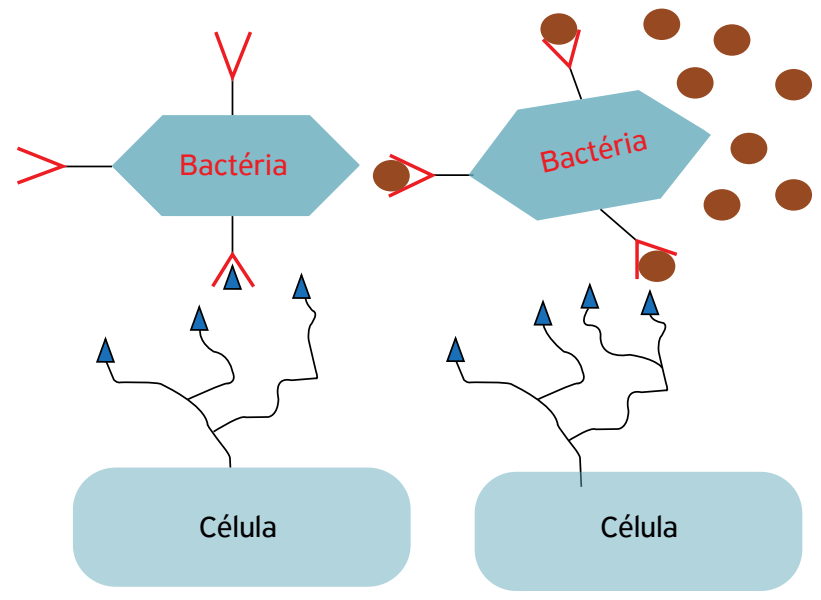

Fonte: adaptado de Gomes (2002).

Figura 2. llustração da ligação do mananoligossacarídeos à bactéria patogênica impedindo sua ligação à célula intestinal. 
da ausência de efeito dos prebióticos sobre a resposta humoral, como foi observado no estudo de Nunes (2008), que, ao avaliar os efeitos de diferentes aditivos, dentre eles o MOS, na resposta imune humoral de frangos de corte, não observou diferenças significativas, aos 42 dias de idade, para a resposta vacinal contra Newcastle.

Melhorias no desempenho das aves têm sido descritas com a utilização de aditivo equilibrador da flora. MAIORKA et al. (2001), estudando o efeito da substituição de antibióticos por prebiótico (MOS) e probiótico (Bacillus subtilis) e a associação de ambos (simbiótico) na dieta sobre o desempenho de frangos de corte, observaram que o pior ganho de peso foi obtido nas aves que náo receberam nenhum tipo de aditivo na dieta (tratamento controle). Aves que não tiveram suplementação apresentaram pior conversão alimentar, quando comparadas com as aves dos demais tratamentos, demonstrando que a substituição de antibióticos por simbióticos na ração é uma alternativa viável, pois não compromete o desempenho das aves. Dimovelis et al. (2003), GARCia et al. (2004) e Ribeiro et al. (2010) notaram melhorias no desempenho após a inclusão do MOS associado ou não com ácidos orgânicos na ração de galinhas poedeiras. Oliveira et al. (2009), ao analisar os efeitos dos níveis de cálcio e da suplementação de dietas com MOS (0 e 0,1\%) sobre o desempenho de codornas em início de postura, concluíram que dietas suplementadas com $0,1 \%$ de MOS reduziram o consumo de raçáo e melhoraram a conversão alimentar. Lemos et al. (2014), ao avaliarem os efeitos do melhor nível de inclusão da parede celular de $S$. cerevisiae na dieta de codornas japonesas em produçáo, também observaram melhorias no desempenho das aves alimentadas com $1,5 \mathrm{~kg} / \mathrm{t}$ de parede celular de S. cerevisiae, quando comparado com tratamento controle (sem inclusão de prebiótico). Em contrapartida, Gноsн et al. (2007) não observaram alteraçóes no desempenho após a inclusão de $1 \mathrm{~g} / \mathrm{kg}$ de MOS nas dietas de codornas japonesas. Estudos realizados com galinhas poedeiras mostraram que o fornecimento de níveis variando de 0,25 a $1,50 \mathrm{~kg} / \mathrm{t}$ de MOS para galinhas poedeiras não influenciou o desempenho dessas aves (Ayanwale et al., 2006; Hosseini et al., 2006; Yousefi; Karkoodi, 2007; Numazaki, 2008).

A qualidade da casca também pode ser afetada positivamente com a adiçấo de prebióticos na ração: Yousefi; KaRKoOdi (2007) observaram melhora no peso da casca em ovos produzidos por poedeiras Hy-Line após adição de MOS $(1,0$ e $1,5 \mathrm{~kg} / \mathrm{t})$. A espessura da casca melhorou após inclusão de $0,1 \%$ de MOS às dietas de codornas japonesas (Oliveira et al., 2009). Lemos et al. (2014) também observaram melhorias na qualidade da casca de ovos produzidos por codornas japonesas após inclusáo de $1,5 \mathrm{~kg} / \mathrm{t}$ de parede celular de $S$. cerevisiae na dieta. No entanto, Costa et al. (2008) não notaram efeito significativo da inclusão de Bio-Mos na dieta de codornas japonesas nos parâmetros de qualidade da casca.
Ribeiro et al. (2010) também não observaram efeito significativo na percentagem de casca após a inclusão de $0,05 \%$ de MOS à dieta de poedeiras Isa Brown.

Melhorias na integridade intestinal das aves de corte e de postura têm sido relatadas em vários estudos que têm evidenciado o efeito benéfico do uso da parede celular de S. cerevisiae sobre o desenvolvimento das vilosidades intestinais, com aumento da altura dos vilos nos três segmentos do intestino delgado, o que pode ser revertido em melhor absorçáo de nutrientes com consequentes melhorias no desempenho e na qualidade dos produtos finais de frangos e de poedeiras (Macari; MaiorKa, 2000; Macari; Furlan, 2005; Yang et al., 2007).

Essa capacidade do MOS de ampliar a área de absorção intestinal é um dos fatores predisponentes para a melhoria da qualidade da casca dos ovos, pois, de acordo com KrUger et al. (2003) e ZAFAR et al. (2004), quando o MOS alcança o intestino grosso, ele é fermentado pela microbiota intestinal e convertido em ácido graxo de cadeia curta (AGCC), o que causa hipertrofia das células da mucosa intestinal, aumentando a superfície de absorçáo. SuZuki; Hara (2004) relataram que os oligossacarídeos podem, igualmente, aumentar a absorçáo de cálcio no intestino delgado pela via paracelular, por meio de estímulo direto sobre o epitélio do intestino delgado, consequentemente melhorando a qualidade da casca.

Em codornas japonesas, tem sido relatada melhoria da integridade intestinal após utilização de aditivos equilibradores da flora na ração. GHosh et al. (2007) observaram aumento na altura das vilosidades intestinais do duodeno, jejuno e íleo de codornas japonesas após inclusão de MOS e ácidos orgânicos na ração. IвrAhim (2011), ao testar MOS + $\beta$-glucano na dieta de codornas japonesas, observou aumento significativo na altura e largura das vilosidades intestinais, quando comparadas com tratamento controle (sem inclusão de MOS + $\beta$-glucano). Lemos et al. (2013) notaram aumento na altura, largura e proporção largura/altura das vilosidades intestinais dos três segmentos (duodeno, jejuno e íleo) de codornas japonesas em produção, melhorando a integridade do epitélio intestinal até a inclusão de $1,7 \mathrm{~kg} / \mathrm{t}$ de parede celular de $S$. cerevisiae na dieta.

As pesquisas com a inclusão de MOS na dieta de frangos de corte apresentaram resultados positivos, com aumento da altura e largura das vilosidades intestinais, como os encontrados por IJı et al. (2001) e MARKovic et al. (2009), e não significativos, tais como os encontrados por Nunes et al. (2009), que náo observaram efeito positivo do MOS sobre a altura das vilosidades intestinais nos três segmentos intestinais (duodeno, jejuno e íleo) dos frangos de corte.

A literatura ainda descreve resultados contraditórios sobre os benefícios de aditivos equilibradores da flora para as aves, em virtude de que há uma diversidade de fatores que podem interferir na eficácia de atuação dessas substâncias, culminando em resultados pouco conclusivos e/ou contraditórios. Entre esses fatores, destacam-se: adaptaçáo da microbiota ao composto adicionado; nível de estresse das aves e, 
especificamente no caso do MOS, em condiçóes de desafio microbiano; excesso no consumo de um prebiótico, levando a um desequilíbrio da microbiota; dosagem e via de administração dos aditivos; diferenças de estrutura química e propriedades físico-químicas dos compostos utilizados como aditivos (Silva; Nornberg, 2003; Hooge, 2004; MoralesLópez et al., 2009).

A utilização dos prebióticos como aditivos equilibradores da flora intestinal na alimentação das aves de corte e de postura tem se tornado uma alternativa natural, baseada em processos preventivos que atuam por meio de diferentes mecanismos que visam não somente a manutenção da saúde intestinal como também um melhor status imunitário, promovendo, dessa forma, resultados impactantes no desempenho produtivo e na qualidade dos ovos, em função do seu efeito positivo sobre o crescimento da população microbiana benéfica, assim como no incremento da integridade intestinal e na ativação do sistema imunológico.

| | | | | | | | | | | | | | | | | | | | | | | | | | | | | | | | | | | | | | | | | | | | | | | | | | | | | | | | | | | | | | | | | | | | | | | | | | | | | | | | | | | | | | | | | | | | | | | | | | | | | | | | | | | | | | | | | | | | | | | | | | | | | | | | | | | | | | | | | | | | | | | | | | | | | | | | | | | | | | | | | | | | | | | | | | | | | | | | | | | | | | | | | | | | | | | | | | | | | | | | | | | | | | | | | | | | | | | | | REFERÊNCIAS

ALLES, M.S.; HARTEMINK, R.; MEYBOOM, S.; HARRYVAN, J.L.; VAN LAERE, K.M.; NAGENGAST, F.M.; HAUTVAST, J.G. Effect of transgalactooligosaccharides on the composition of the human intestinal microflora and on putative risk markers for colon cancer. The American Journal of Clinical Nutrition, v.69, p.980-991, 1999.

AYANWALE, B.A.; KPE, M.; AYANWALE, V.A. The effect of supplementing saccharomyces cerevisiae in the diets on egg laying and egg quality characteristics of pullets. International Journal of Poultry Science, v.5, p.759-763, 2006.

BIGGS, P.; PARSONS, C.M.; FAHEY, G.C. Effects of several oligosaccharides on growth performance, nutrient digestibilities, and caecal microbial populations in young chicks. Poultry Science, v.86, p.2327-2336, 2007.

BOUHNIK, Y.; FLOURIE, B.; D'AGAY-ABENSOUR, L.; POCHART, P.; GRAMET, G.; DURAND, M.; RAMBAUD, J.C. Administration of transgalactooligosaccharides increases fecal bifidobacteria and modifies colonic fermentation metabolism in healthy humans. Journal of Nutrition, v.127, p.444-448, 1997.

CASTANON, J.I.R. History of the use of antibiotic as growth promoters in European Poultry Feeds. Poultry Science, v.86, p.2466-2471, 2007.

COMPÊNDIO BRASILEIRO DE ALIMENTAÇÃO ANIMAL. SUmário: Guia de aditivos. São Paulo: Sindicações, 2009.

COSTA, F.G.P.; NOBRE, I.S.; SILVA, L.P.G.; GOULART, C.C.; FIGUEIREDO, D.F.; RODRIGUES, V.P. The use of prebiotic and organic minerals in rations for japonese laying quail. International Journal of Poultry Science, v.7, n.4, p.339-343, 2008.

COTTER, P.F. Modulation of immune response: current perceptions and future prospects with an example from poultry. In: ALLTECH'S ANNUAL SYMPOSIUM ON 90 BIOTECHNOLOGY IN FEED INDUSTRY, 10., 1994, Nottingham. Proceedings... Loughborough, UK: Nottingham University Press, 1994. p. 105-203.

DIMOVELIS, P.; CHRISTAKE, E.; TSEVERINI-GOUSSI, A.; SPAIS, A.B. Effect of Bio-Mos on growth, egg production and egg quality of Lohmann brown layers. In: ALLTECH'S ANNUAL NUTRITIONAL BIOTECHNOLOGY IN THE FEED AND FOOD INDUSTRIES, 19., 2003, Lexiton. Proceedings... Lexiton, Ky: [s.n.], 2003.
DIONÍZIO, M.A.; BERTECHINI, A.G.; KATO, R.K.; TEIXEIRA, A.S. Prebiótico como promotor de crescimento para frangos de cortedesempenho e rendimento de carcaça. Ciência Agrotécnica, n.3, p.1580-1587, 2002.

DONALSON, L.M.; KIM, W.K.; CHALOVA, V.I.; HERRERA, P.; WOODWARD, C.L.; MCREYNOLDS, J.L.; KUBENA, L.F.; NISBET, D.J.; RICKE, S.C. In vitro anaerobic incubation of Salmonella enterica serotype Typhimurium and laying hen cecal bacteria in poultry feed substrates and a fructooligosaccharide prebiotic. Anaerobe, lowa, v.13, n.5-6, p.208-214, 2007.

FERREIRA. A.P.; ASTOLFI-FERREIRA, C.S. Medidas inespecíficas para o controle bacteriano. In: SIMPÓSIO BRASIL SUL DE AVICULTURA, Chapecó, 2006, Anais... Chapecó, 2006. p.56-66.

GARCIA, N.L.; CACHALDORA, P.; TUCKER, L. BAUCELLS, F.; NEDEL, $P$. Effect of mannanoligossacharides suplementation to laying hen diets. Poultry Science, n.83, Supplement 1, p.397, 2004.

GIBSON, G.R.; ROBERFROID M.B. Dietary modulation of the human colonic microbiota: introducing the concept of prebiotics. Journal of Nutrition, v.125, n.6, p.1401-1412, 1995.

GOMES, M.A.B. Aditivos Probióticos, Prebióticos e Simbióticos na Alimentação Animal. Disponível em: <www.mariboi.com.br/_ assets/artigos/13_artigo.pdf, 2002>. Acesso em: 15 abr. 2011.

GOSH, H.K.; HALDER, G.; SAMANTA, G.; PAUL, S.K.; PYNE, S.K. Effect of dietary supplementation of organic acid and mannanoligosaccharide on the performance and gut health of japonese quail (Coturnix coturnix japonica). Asian Journal of Poultry Science, v.1, n. 1, p.1-7, 2007.

HOOGE, D. Dietary alternatives for improving live performance of antibiotic-free poultry. International Journal of Poultry Science, v.3, p.163-174, 2004.

HOSSEINI, S.A.; LOTFOLLAHIAN, H.; KAMYABAND, A.; MADHAVI, A Study on the effect of yeast (Saccharomyces cerevisiae) utilization on the commercial layer hen's performance. Pakistan Journal of Biological Sciences, v. 12, p.2346-2349, 2006.

IBRAHIM, Z.A. Modulation of immunity and some biological functions of japonese quail by mannan oligosaccharide and B-glucan administration. Egypt Poultry Science, v.31, p.867-882, 2011. 
IJI, P.A.; TIVEY, D.R. Natural and synthetic oligosaccharides in broiler chicken diets. World Poultry Science Journal, v.54, p.129-143, 1998.

IJI, P.A.; SAKI, A.A.; TIVEY, D.R. Intestinal structure and function of broiler chickens on diets supplemented with a mannanoligosaccharide. Journal of the Science of Food and Agriculture, v.81, n.12, p.1181-1192, 2001.

JUNG, S.J.; HOUDE, R.; BAURHOO, B.; ZHAO, X.; LEE, B.H. Effects of galacto-oligosaccharides and a Bifidobacteria lactis-based probiotic strain on the growth performance and fecal microflora of broiler chickens. Poultry science, v.87, n.9, p. 1694-1699, 2008.

KNUDSEN, K.E.B.; HESSOV, I. Recovery of inulin from Jerusalem artichoke (Helianthus tuberosus L.) in the small intestine of man. British Journal of Nutrition, v.74, p.101-113, 1995.

KOGAN, G.; KOCHER, A. Role of yeast cell wall polysaccharides in pig nutrition and health protection. Livestock Science, v.109, p. 161-165, 2007.

KRUGER, M.C.; BROWN, K.E.; COLLETT, G.; LAYTON, L.; SCHOLLUM, L.M. The effect of fructooligosaccharides with various degrees of polymerization on calcium bioavailability in the growing rat. Experimental Biology and Medicine, v.228, p.683-688, 2003.

LEMOS, M.J.; CALIXTO, L.F.L.; NASCIMENTO, A.A.; SALES, A.; SANTOS, M.A.; AROUCHA, R.J.N. Morfologia do epitélio intestinal de codornas japonesas alimentadas com parede celular da Saccharomyces cerevisiae. Ciência Rural, v.43, n.12, p.2221-2227, 2013.

LEMOS, M.J.; CALIXTO, L.F.L.; LIMA, C.A.R.; REIS, T.L.; REGO, R.S.; NAK, S.Y.; AROUCHA, R.J.N. Níveis de prebiótico na dieta sobre o desempenho e a qualidade de ovos de codornas japonesas. Revista Brasileira de Saúde e Produção Animal, v.15, n.3, p.614-626, 2014.

LODDI, M.M. Probióticos, prebióticos e acidificantes orgânicos em dietas para frangos de corte. Tese (Doutorado em Zootecnia) Universidade Estadual Paulista "Júlio de Mesquita Filho", Jaboticabal, 2003.

MACARI, M.; MAIORKA, A. Função gastrintestinal e seu impacto no rendimento avícola. In: CONFERÊNCIA APINCO DE CIÊNCIA E TECNOLOGIA AVÍCOLAS, 2., 2000, Campinas. Anais... Campinas: FACTA, 2000. p.161-174

MACARI, M.; FURLAN, R.L. Probióticos. In: CONFERÊNCIA APINCO DE CIÊNCIA E TECNOLOGIA AVÍCOLAS, 1., 2005, Campinas. Anais... Campinas: FACTA, 2005. p.53-71.

MAIORKA, A.; SANTIN, E.; SUGETA, S.M.; ALMEIDA, J.G.; MACARI, M. Utilização de prebióticos, probióticos ou simbióticos em dietas para frangos. Revista Brasileira de Ciência Avícola, v.3, p.75-82, 2001.

MARKOVIC, R.; SEFER, D.; KRSTIC, M.; PETRUJKIC, B. Effect of different growth promoters on broiler performance and gut morphology. Archivos de Medicina Veterinária, v.41, p.163-169, 2009.

MATHEUS, K.M.; BERNSTEIN, J.R.; BUZBY, J.C. International Trade of Meat/Poultry Products and Food Safety Issues. Washington, DC: Economic Research Service/USDA, 2003. p.49-73.
MORALES-LÓPEZ, R.; AUCLAIR, E.; GARCÍA, F.; ESTEVE-GARCIA, E.; BRUFAU,

J. Use of yeast cell walls; $\beta-1,3 / \beta-1,6$ glucans; and mannoproteins in broiler chicken diets. Poultry Science, v.88, p.601-607, 2009.

NEWMAN, K. Form follows function in picking MOS product. Feedstuffs, v.79, n.4, 2007.

NUMAZAKI, E.M. Adição de mananoligossacarídeos e halquinol em dieta de poedeiras Bovans White. Dissertação (Mestre em Ciências Agrárias) - Universidade de Brasília, 2008.

NUNES, A.D. Influência do uso de aditivos alternativos a antimicrobianos sobre o desempenho, morfologia intestinal e imunidade de frangos de corte. Dissertação (Mestrado em Medicina Veterinária) - Universidade de São Paulo, São Paulo, 2008.

NUNES, A.D.; VAZ, A.C.N.; RASPANTINI, L.E.; SILVA, E.M.; ALBUQUERQUE, R. Desempenho e morfologia intestinal de frangos de corte alimentados com rações contendo aditivos alternativos a antimicrobianos. Brazilian Journal of Veterinary Research and Animal Science, v.46, n.6, 2009.

OLIVEIRA, M.C.; MACHADO, M.G.; GONÇALVES, B.N.; MACEDO, C.M.R.; ASSIS, F.A. Dietas com mananoligossacarídeo e níveis reduzidos de cálcio para codornas japonesas. Revista Brasileira de Zootecnia, v.38, n.11, p.2193-2197, 2009.

OTUTUMI, L.K.; FURLAN, A.C.; NATALI, M.R.M.; MARTINS, E.N.M.; LODDI, M.M.; OLIVEIRA, A.F.G. Utilização de probiótico em rações com diferentes níveis de proteína sobre o comprimento e a morfometria do intestino delgado de codornas de corte. Acta Scientiarum. Animal Sciences, v.30, n.3, p.283-289, 2008.

PELICANO, E.R.L.; SOUZA, P.A.; SOUZA, H.B.A. Prebióticos e probióticos na nutrição de aves. Revista Ciências Agrárias e da Saúde, v.2, n. 1 p.59-64, 2002.

PELÍCIA, K. Efeito de promotores biológicos e químicos sobre o desempenho, rendimento de carcaça e qualidade da carne em frangos de corte tipo colonial. Dissertação (Mestrado em Zootecnia) Universidade Estadual Paulista, Botucatu, 2004.

RIBEIRO, C.L.G.; RUTZ, F.; DALLMANN, P.R.; ZAUK, N.F.; SILVEIRA, M.H.D.; GONÇALVES, R.A.S.; ANCIUTI, M.A.; ROSSI, P. Efeito da utilização de mananoligossacarídeos (MOS) e de ácidos orgânicos associados à MOS, com e sem antibióticos, na dieta de poedeiras produtoras de ovos avermelhados. Ciência Animal Brasileira, v. 11 , n.2, p.292-300, 2010.

ROWLAND, I.R. Metabolic interactions in the gut. In: FULLER, R. (Ed.). Probiotics: the scientific basis. London: Chapman and Hall, 1992. p.29-53.

SALYERS, A.A. Agricultural use of antibiotics and antibioticresistance in human pathogens: is there a link? In: ALLTECH.SANNUAL SYMPOSIUM, 15., Nottingham. Proceedings... Nottingham: Alltech, 1999. p. 155-171.

SHANE, M.S. Mannan oligosaccharides in poultry nutrition: mechanism and benefits. Science and technology in the feed industry. Nottingham, UK: Nottingham, 2001. p.65-77. 
SANTIN, E.; MAIORKA, A.; MACARI, M.; GRECCO, M.; SANCHEZ, J.C.; OKADA, T. M.; MYASAKA, A.M. Performance and intestinal mucosa development of broiler chickens fed diets containing Saccharomyces cerevisiae cell wall. Journal Applied Poultry Research, v.10, p.236-244, 2001.

SAVAGE, T.F.; ZAKREWSKA, E.I.; ANDREASEN, J.R. The effects of feeding mannan oligosaccharide supplemented diets to poultrys on performance and the morphology of the small intestine. Poultry Science, v.76, p.139, 1997.

SCAPINELLO, C.; FARIA, H.G.; FURLAN, A.L.; MICHELAN, A.C. Efeito da utilização de oligossacarídeo manose e acidificantes sobre o desempenho de coelhos em crescimento. Revista Brasileira de Zootecnia, v.30, p.1272-1277, 2001

SILVA, L.P.; NORBERG, J.L. Prebióticos na nutrição de não ruminantes. Ciência Rural, v.33, n.5, p.983-990, 2003.

SPRING, P.; WENK, C.; DAWSON, A.; NEWMAN, K.E. The effect of dietary mannanoligosaccharides on cecal parameters and the concentrations of enteric bacteria in the ceca of Salmonellachallenged broiler chicks. Poultry Science, Champaign, v.79, n.2, p.205-211, 2000.

SPRING, P.; PIRVULESCU, M. Mannanoligosaccharide: Its logical role as natural feed additive for piglets. In: BIOTECHNOLOGY IN THE FEED INDUSTRY ANNUAL SYMPOSIUM, 13, Norttingham. Proceedings... Norttingham: Norttingham University Press, p.553, 1998.
SUZUKI, T.; HARA, H. Various non-digestible saccharides increase intracellular calcium ion concentration in rat small-intestinal enterocytes. British Journal Nutrition, v.92, p.751-755, 2004.

YANG, Y.; IJI, P.A.; KOCHER, A.; MIKKELSEN, L.L.; CHOCT, M. Effects of mannanoligosaccharide on growth performance, the development of gut microflora, and gut function of broiler chickens raised on new litter. Journal Applied Poultry Research, v.16, p.280-288, 2007.

YOUSEFI, M.; KARKOODI, K. Effect of probiotic Thepax ${ }^{R}$ and Saccharomyces cerevisiae supplementation on performance and egg quality of laying hens. International Journal of Poultry Science, v.6, n. 1, p.52-54, 2007.

ZAFAR, T.A.; WEAVER, C.M.; ZHAO, Y.; MARTIN, B.R.; WASTNEY, M.E. Non digestible oligosaccharides increase calcium absorption and suppress bone resorption in ovariectomized rats. Journal of Nutrition, v.134, p.399-402, 2004

ZAGHINI, A.; MARTELLI, G.; RONCADA, P.; SIMIOLI, M.; RIZZI, L. Mannanoligosaccharides and Aflatoxin B1 in feed forlaying hens: effects on egg quality, Aflatoxins $B 1$ and $M 1$ residues in eggs, and Aflatoxin B1 levels in liver. Poultry Science, v.84, p.825-832, 2005

XU, Z.R.; HU, C.H.; XIA, M.S.; ZHAN, X.A.; WANG, M.Q. Effects of dietary fructooligosaccharide on digestive enzyme activities, intestinal microflora and morphology of male broilers. Poultry Science, v.82, p.1030-1036, 2003. 